\title{
Principal Components and Classification Analysis of Manganese Content in Spring of Perennial Grassland Forage from Microecosystems of Banat Hills
}

\author{
Monica HARMANESCU* \\ Faculty of Agricultural Sciences, Banat's University of Agricultural Sciences and Veterinary Medicine \\ "Regele Mihai I al Romaniei" from Timisoara, Calea Aradului, no.119, 300645, Timisoara, Romania. \\ *corresponding author: monica.harmanescu@yahoo.com
}

Bulletin UASVM series Agriculture 77(1) / 2020

Print ISSN 1843-5246; Electronic ISSN 1843-5386

DOI:10.15835/buasvmcn-agr: 2018.0031

\begin{abstract}
The purpose of this research was to monitor the manganese (Mn) content of forage from perennial grassland microecosystems situated in the west part of Romania. Mineral and organic fertilization, since 2003, influenced the microecosystems conditions. It was used fermented sheep manure as organic fertilizer. Calamagrostis epigejos, Festuca rupicola and Trifolium repens represented mainly the Poaceae and Fabaceae families of grassland floristic matrix. It was determined the spring Mn content in the middle and at the end of May by ContrAA300 HighResolution Continuum Source spectrometer of Analytik Jena. It was selected a number of 17 variables to compute the PC\&CA model. The first three components described around 75\% of total variance. The correlation coefficients for spring Mn contents of forage and mineral fertilization data were high, in $0.6-0.9$ range. The correlation coefficients between fermented sheep manure data and spring Mn contents of forage were negatively.
\end{abstract}

Keywords: fertilization, grassland, heavy metals, multivariate analysis.

\section{INTRODUCTION}

To monitor the qualitative parameters of the grassland floristic symphony, as source of forage for animals feeding, must be a guaranty to obtain a qualitative row matter with animal origin for food industry. Manganese (Mn) is one of the most important parameter that it is recommendable to be quantifying for forage quality characterization.

The state of art highlights manganese both as essential and potential toxic element. Organisms need $\mathrm{Mn}$ as essential mineral for surviving, especially as astrocytes (Erikson and Aschner, 2006) and metalloenzymes constituent (Kizaki et al. 1993; Cailliatte et al. 2010; Eijkelkamp et al., 2014). Mn is involved in DNA synthesis, carbohydrates and proteins metabolism (Cailliatte et al. 2010; Markiewicz-Górka et al. 2015), protection against the oxidative stress (Kizaki et al. 1993; Hur et al., 2003; Holley et al., 2011; Eijkelkamp et al., 2014; Markiewicz-Górka et al. 2015), photosynthesis (Millaleo et al., 2010; Fernando and Lynch, 2015; Leplat et al., 2016), etc.

According with Neal and Guilarte (2012), $\mathrm{Mn}$ is the second heavy metal, following iron, as abundance. The oxidation state of $\mathrm{Mn}$ in soil can be 0 , II, III, IV, VI and VII. In vegetal and animal organism Mn can be find in II, III and IV oxidation state, the most bioavailable being divalent manganese (Millaleo et al., 2010; Fernando and Lynch, 2015). In plant, $\mathrm{Mn}$ is responsible for the activation of more than 35 enzymes (Leplat et al., 2016). Mn content under the necessary request quantity can be dangerous for the plants chloroplasts (Millaleo et al., 2010), being 
responsible for decreasing of the plants growth and productivity, lower resistance to the pathogens and tolerance against the freezing temperature (Socha and Guerinot, 2014). In animal organism, the $\mathrm{Mn}$ nutritional necessary depends by the species, age and physiological stage. In UE, the maximum authorized $\mathrm{Mn}$ total content in animal diet for food-industry is $150 \mathrm{mg} / \mathrm{kg}$ (RegisterEC-No 1831/2003). According with Hidiroglou (1979) and Kisidayova et al. (2018), ruminants used only $1 \%$ of the Mn from the diet. That's way, for an optimum performance of ruminants, it is recommended minimum $40 \mathrm{mg} \mathrm{Mn} / \mathrm{kg}$ in the forage (Khan et al., 2015; Hidiroglou, 1979). Below this limit, it is possible to appear imbalance of $\mathrm{Mn}$ bioavailability in ruminant feed. In sheep case, Zhang etal. (2018) recommended $3.7 \mathrm{mg} / \mathrm{kg} \mathrm{BW} / \mathrm{d}$ as net $\mathrm{Mn}$ necessary for maintenance. Mn deficit in animals could generate fertility problems, for both male and female, correlated with functional deficiencies of some endocrine glands (Kumar et al., 2011).

On the other side, as potential toxic element, Mn was reported especially related with chronic inhalation as oxides (Cailliatte et al. 2010; Frick et al., 2011), in case of doses higher than the threshold limit value established at $1 \mathrm{mg} /$ m3,according with NIOSH standards (Erikson and Aschner, 2006; Mirmohammadi, 2014). In human and animal organisms, Mn toxicity can generate neurodegenerative disorder and neuropsychiatric disturbances at central nervous system level (Erikson and Aschner, 2006; Santamaria, 2008; Bhuvaneswari et al., 2014; Mirmohammadi, 2014; Markiewicz-Górka et al. 2015), cancer (Zhang et al. 2014; Kim et al. 2017) and other chronic diseases. Researches on rats' brain, made by Bhuvaneswari et al. (2014), have shown significant results regarding the a-tocopherol protective role against the Mn toxicity effects.

Mn phytotoxicity, as stress factor in plants in natural systems, was reported by Schubert (1992) and Fernando and Lynch (2015). They indicated as symptoms for Mn toxicity the leaf interveinal chlorosis and darkening of old foliage. One of the most important factors that determine the $\mathrm{Mn}$ phytotoxicity is the soil $\mathrm{pH}$ under 5.0, followed by irrational application of Mn foliar fertilizers (Schubert, 1992).

The aim of this research was to extract valuable information of spring $\mathrm{Mn}$ content of forage from perennial grassland microecosystems situated in the west part of Romanian Banat hill region by Principal Components \& Classification Analysis multivariate technique (StatSoft - Statistica Version 10), depending on floristic matrix, soil and fertilization data.

\section{MATERIALS AND METHODS}

It was situated in Banat, Romania (N: 4512' latitude; E: 21 ${ }^{\circ} 60^{\prime}$ longitude), the selected perennial grassland microecosystems fertilized since 2003. Calcic Luvisol characterized the grassland. In Banat County is temperate continental with Mediterranean influences clime. The soil multiannual average temperature (5-10 $\mathrm{cm}$ ) is generally under 0period, and higher than $500 C$ in December-January $C$ beginning with the second decade of April (Ianos et al., 1997).

According to the Meteorological Station Archive (Oravita, Caras-Severin), the number of the days with temperature higher than $25^{\circ} \mathrm{C}$ in December 2007-March 2008 period was zero, while in April 2008 and May 2008 was 1 day, respectively 11 days. The temperatures under $0^{\circ} \mathrm{C}$ recorded in 23 days of December 2007, in 17 days of January 2008, in 10 days of February 2008 and in 4 days of March 2008. During April-May 2008 period was not detected temperatures under $0^{\circ} \mathrm{C}$ in the grassland microecosystems (Meteorological Station Archive of Oravita, Caras-Severin).

Harmanescu (2012) described the perennial grassland experimental site organizing and fertilization management systems. Mineral fertilizers were superphosphate, ammonium nitrate, potassium salt and NPK mineral complex. The organic fertilizer applied was fermented sheep manure, with $390 \mathrm{ppm} \mathrm{Mn}(\mathrm{U}=61 \%)$. The microecosystems notation was the following: 01-03 for exclusive organic fertilization, OM1-OM3 for mixed organic - mineral fertilizers application and M1-M3 for exclusive mineral fertilization system. The unfertilized case was distinct identified by "M". Five replications for each microecosystem were organized $(25 \mathrm{~m} 2 /$ trial), in complete randomized block design.

The spring Mn content in the middle and at the end of May was monitor by ContrAA300 HighResolution Continuum Source spectrometer of Analytik Jena. The vegetal samples burn, the Mn extraction protocol, the percent recovery mean and detection limit, and the Mn quantification using 
flame atomic absorption spectrometry procedure were described by Gergen and Harmanescu (2012). It was reported as ppm the results for Mn content. It was determined the soil hydrolysis $\mathrm{pH}$ values respecting SR ISO 10390/1999. It was quantified the humus content by Walklay Black - Gogoasa, the soil total nitrogen content by Kjeldahl method and phosphorus/potassium content in mobile form by Egner-Riehm-Domingo method (Stoica et al., 1986). Floristic matrix was established gravimetric as \%. It was used a number of 17 variables to compute the PC\&CA by StatSoft - STATISTICA Version 10.

\section{RESULTS AND DISCUSSIONS}

In Romania, the grassland forage is one of the most important feed resources for ruminants for more than 8 months yearly, during all spring, summer and autumn. Only in winter (late November to the first decade of March), the ruminants are kept and feed indoor when the negative temperatures determine a forage deficit. That's way is recommendable that farmers develop a sustainable pastoral system when design the grassland management, especially in perennial grassland case. Can be PC\&CA a flexible and useful tool for Mn content monitoring in different grassland management in terms of floristic matrix components, soil characteristics and fertilization data?

For PC\&CA multivariate model, in this research a number of 17 variables were selected, separated in two main groups: 15 active variables (the microecosystems conditions) and 2 supplementary variables (representing the spring $\mathrm{Mn}$ content of forage from perennial grassland microecosystems of Banat County in the middle and at the end of May).

Regarding the supplementary variables, in normal soil and clime conditions of Banat hills, without fertilization, the perennial grassland forage had $100 \mathrm{ppm} \mathrm{Mn}$ in the middle of May and $86 \mathrm{ppm} \mathrm{Mn}$ at the end of May. The exclusive fermented sheep manure application at each two years, since 2003, decreased the spring Mn content of grassland forage reported to unfertilized microecosystem, the average values being 89 ppm in the middle of May and 66ppm at the end of May. Mineral fertilizers applied in perennial grassland microecosystems increased the $\mathrm{Mn}$ content of forage, mixed or not with fermented sheep manure, in both studied periods, reported to unfertilized and exclusive organic fertilized management systems. The mineral-organic fertilization increased the Mn content of forage to $168 \mathrm{ppm}$ in the middle of May, and to $88 \mathrm{ppm}$ at the end of May, while exclusive mineral fertilization to $222 \mathrm{ppm}$, respectively $141 \mathrm{ppm}$.

The 15 active variables of PC\&CA model were: soil characteristics $(\mathrm{pH}$, Humus, nitrogen content by Kjeldahl method, phosphorus - Pm and potassium - Km content in mobile form), fermented sheep manure and NPK mineral fertilization data and floristic matrix represented by Ce\% - Calamagrostis epigejos, Fr\% - Festuca rupicola, Tr\% - Trifolium repens, Fv\% - Filipendula vulgaris, Ib Inula britanica and Rc\% - Rosa canina.

The soil humus in unfertilized microecosystem was $5.8 \%$. Organicfertilizationincreased the humus average value to $6.3 \%$ in 01-03 microecosystems, with the increasing the fermented sheep manure dose, and to $7.3 \%$ in OM1-OM3 microecosystems. In exclusive mineral fertilization cases, the average value of soil humus was $6.3 \%$.

The soil $\mathrm{pH}$ was 6.1 in the normal conditions of spring Banat hill without fertilization (M case). The soil $\mathrm{pH}$ values increased with the increasing of fermented sheep doses in exclusive organic fertilized microecosystems, the average value being 6.2. Also 6.2 was the average value of soil $\mathrm{pH}$ for $\mathrm{OM} 1$ and $\mathrm{OM} 2$, while in OM3 case decreased to 6.1. In exclusive mineral fertilized microecosystems, the average value of soil $\mathrm{pH}$ was 5.8.

To complete more the soil characteristics of perennial grassland microecosystems, it was determined the phosphorus - mobile form (ppm), potassium - mobile form (ppm) and Kjeldahl nitrogen content (\%). Phosphorus and potassium contents in mobile form, quantified in the unfertilized grassland microecosystem, were 58 ppm, respectively $209 \mathrm{ppm}$. Reported to the natural soil conditions of Banat hill, the fertilization with fermented sheep manure, exclusive or mixed with mineral fertilizers, or only exclusive by mineral fertilizers (NPK), increased the $\mathrm{Pm}$ and $\mathrm{Km}$ average values: $68 \mathrm{ppm}$ and $219 \mathrm{ppm}$ (01-03); 78 ppm and 230ppm (OM1-OM3); $61 \mathrm{ppm}$ and 219 ppm (M1-M3). Comparatively with unfertilized perennial grassland microecosystem, where the Kjeldahl soil nitrogen was $0.26 \%$, the organic and mineral fertilization, exclusive or mixed, increased the average values of this qualitative indicator of 
soil to $0.37 \%$ in $01-03,0.35 \%$ in $0 \mathrm{M} 1-0 \mathrm{M} 3$ and $0.31 \%$ in M1-M3 cases.

The symphony of plant species matrix represents always a natural mirror of grassland forage nutritive and energetic quality. The dairy and beef ruminants' production and animal performance depend by the nutrients management of grassland forage. The high diversity of valuable plants species, which complete the floristic puzzle of Banat hill perennial grasslands covering, can assure an animal feeding rich in many valuable nutrients. From spring to the late autumn, in the studied perennial grassland covering it was identified more than 50 plants species as biomass components from Poaceae, Fabaceae and others botanical families. A number of 6 parameters representatives for perennial grassland floristic matrix were selected for PC\&CA model.

In spring, in the soil, temperature and rainfall conditions of Banat hill, Calamagrostis epigejos (Ce\%) and Festuca rupicola (Fr\%) were quantified gravimetrically in the highest percents from Poaceae family. Ce\% was not detected in unfertilized microecosystem in May. In organic farming microecosystems, the average value of $\mathrm{Ce} \%$ presence was $4 \%$ and in organic-mineral mixed fertilization management increased to $5 \%$. The exclusive mineral fertilization management stimulated the presence of $\mathrm{Ce} \%$, the average value being $45 \%$. In Fr\% case, the different fertilization managements decreased its presence in perennial grassland microecosystems, from $37 \%$ in unfertilized case, to the following average values: 10\% (01-03), 16\% (OM1-OM3) and 24\% (M1-M3) respectively, in this period of the year.

Trifolium repens $(\mathrm{Tr} \%)$ was the native plant dominant of Fabaceae family in the grassland covering in spring conditions of Banat hill. When the dynamic of soil nutrients, clime conditions and fertilization management of grassland are optimum, the presence of this plant achieved even 46\% (02) in perennial forage biomass of grassland. The average value of $\mathrm{Tr} \%$ presence in the forage of grassland microecosystems fertilized exclusive with fermented sheep manure was $43 \%$. In organic - mineral fertilization management (OM1-OM3), the forage of grasslands microecosystems had 18\% Tr\% (average value), $27 \%$ in $\mathrm{OM} 1$ and OM2 (average value) and 1\% in OM3 because of fertilization with a supplement of $50 \mathrm{~kg} / \mathrm{ha}$ mineral nitrogen. In OM3 was quantified gravimetrically the same presence of $\operatorname{Tr} \%$ as in unfertilized grassland microecosystem (M). In M1-M3 cases, the presence of Tr\% was under $0.5 \%$ because of the substances flows and soil conditions influenced by the exclusive NPK mineral fertilization management.

From others botanical families were identified in the highest quantity Inula britanica (Ib\%), Filipendula vulgaris (Fv\%) and Rosa canina (Rc\%), the last being inconsumable for animals. In $\mathrm{M}$ microecosystem, which reflects the substances flows in soil and clime conditions without fertilizers influence, the presence of Fv\% and Rc\% was the highest for both plant species, $10 \%$ and $11 \%$ respectively, while for $\mathrm{Ib} \%$ was the smallest for the studied period: $3 \%$. In exclusive organic fertilization (0103), the forage had the following Ib\%/Fv\%/ Rc\% average values profile: $8 \% / 6 \% / 3 \%$. In exclusive mineral fertilization system (M1-M3) the forage had the following Ib\%/ $\mathrm{Fv} \% / \mathrm{Rc} \%$ average values profile: $5 \% / 7 \% / 2 \%$, while in perennial grassland microecosystems fertilized mixed organic - mineral the average values profile was $7 \% / 6 \% / 3 \%$.

It was introduced all these 17 variables (supplementary and active) in StatSoft - STATISTICA (Version 10) matrix to compute the PC\&CA model. PC\&CA was tested that can be use as flexible and comprehensive tool to extract valuable information regarding the spring $\mathrm{Mn}$ content of forage from grassland microecosystems influenced by organic and/or mineral fertilization. The active variables of PC\&CA multivariate model reflected the soil, fertilization management and the floristic matrix fingerprinting impact in clime conditions of Banat hill on the supplementary variables - the Mn content in the middle and at the end of May of the forage from perennial grassland microecosystems.

After the PC\&CA multivariate model was computed, it was analyzed the facilities of this statistic tool to extract accessible information from the representative variables which characterized the studied natural process. A number of nine components described $100 \%$ the quality of the PC\&CA model. The first three principal components (PC) described around $75 \%$ of total variance, while PC1 and PC2 represented more than 61\%. The eigenvalues of the first three principal components of PC\&CA statistical approach were 5.81, 3.43, and 
respectively 1.99. The factor loadings of PC1, PC2 and PC3 are in Tab. 1.

The highest positive impact on PC1 had soil pH, soil Kjeldahl N (\%), soil Pm (ppm), Tr\% presence in grassland biomass and organic fertilization data, while negative values had the following parameters: spring $\mathrm{Mn}$ content in the middle and at the end of May, $\mathrm{Ce} \%$ presence in grassland biomass and NPK mineral fertilization data. The representative variables of PC2 with a positive impact were $\mathrm{Fv} \%$ and $\mathrm{Rc} \%$, while negative values had soil Kjeldahl N (\%), Humus (\%), soil Pm and $\mathrm{Km}(\mathrm{ppm})$ and mineral PK fertilization data. On PC3 the Humus (\%) and Rc\% variables had the highest positive impact.

In Figure 1 the classification of all ten microecosystems of perennial grassland from Banat hill is presented.

Figure 1 reflects in a comprehensive 2D manner the distribution of all 10 studied microecosystems of Banat perennial grassland in five main groups based on acquired data.
First distinct group classified the exclusive organic and mixed fertilized microecosystems 02 , 03, OM1 and OM2. The second group classified the exclusive mineral fertilized microecosystems M1, M2 and M3 based on the selected quantitative characteristics. The mixed organic - mineral fertilized grassland microecosystem OM3 represented the third group, separated by OM1 and $0 \mathrm{M} 2$ because of the recorded data influenced by the application of $50 \mathrm{~kg} / \mathrm{ha}$ mineral nitrogen supplement. The fourth and fifth groups from Figure 1 highlighted the unfertilized $M$ and exclusive organic fertilized 01 microecosystems based on recorded multiresponse.

With regard to the monitored variables distribution, the PC\&CA multivariate approach fitted 2D in Figure 2 has good predictive power from the point of view of spring $\mathrm{Mn}$ content monitoring for the forage from the studied microecosystems, based on soil, floristic biomass and fertilization data, heaving practical facilities as tool in grassland management.

Table 1. The factor loadings of PC\&CA statistical approach (PC1, PC2 and PC3)

\begin{tabular}{cccc}
\hline Variables/PCs & PC $\mathbf{1}$ & PC $\mathbf{2}$ & PC $\mathbf{3}$ \\
\hline $\mathbf{O}$ & 0.928 & -0.197 & -0.115 \\
\hline $\mathrm{N}$ & -0.821 & -0.406 & -0.222 \\
\hline $\mathrm{P}$ & -0.541 & -0.677 & 0.204 \\
\hline $\mathrm{K}$ & -0.675 & -0.591 & 0.248 \\
\hline Soil pH & 0.909 & 0.152 & 0.345 \\
\hline Humus & 0.307 & -0.610 & 0.543 \\
\hline Soil N & 0.678 & -0.517 & -0.231 \\
\hline $\mathrm{Pm}$ & 0.555 & -0.541 & 0.487 \\
\hline $\mathrm{Km}$ & 0.228 & -0.730 & 0.331 \\
\hline $\mathrm{Ce} \%$ & -0.691 & -0.421 & -0.441 \\
\hline $\mathrm{Fr} \%$ & -0.440 & 0.369 & 0.361 \\
\hline $\mathrm{Tr} \%$ & 0.871 & 0.046 & -0.236 \\
\hline $\mathrm{Ib} \%$ & 0.450 & 0.114 & -0.324 \\
\hline $\mathrm{Fv} \%$ & -0.353 & 0.479 & 0.486 \\
\hline $\mathrm{Rc} \%$ & -0.165 & 0.610 & 0.545 \\
\hline$* \mathrm{Mn} 1$ & -0.708 & -0.501 & -0.042 \\
\hline$* \mathrm{Mn} 2$ & -0.859 & -0.359 & -0.024 \\
\hline
\end{tabular}

Note: *supplementary variables; Mn 1 - spring content in the middle of May (ppm); Mn 2 - spring content at the end of May (ppm); soil Km and Pm (ppm); soil Kjeldahl nitrogen (\%); Humus (\%). 


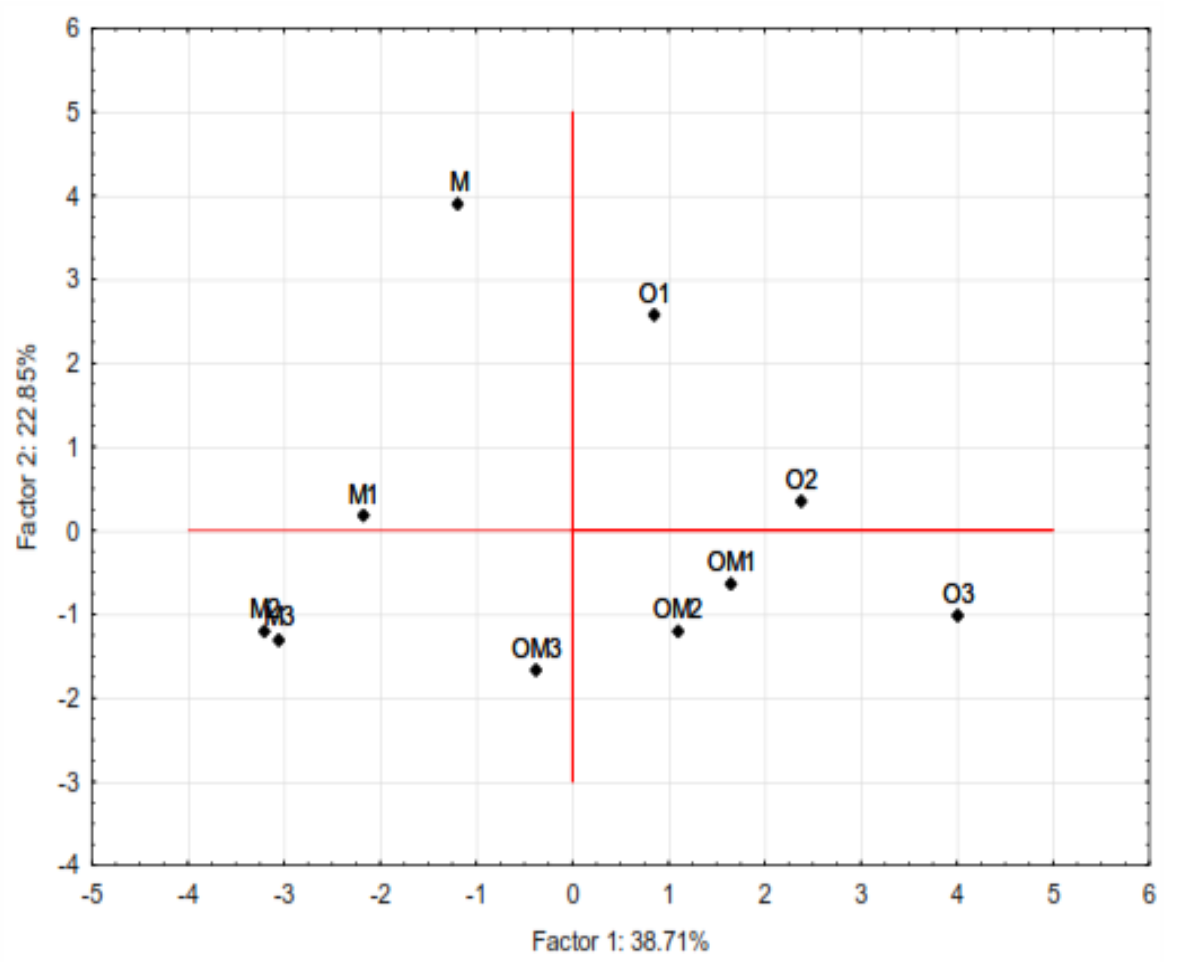

Figure 1. The PC\&CA projection of the 10 microecosystems conditions on PC1xPC2 plane

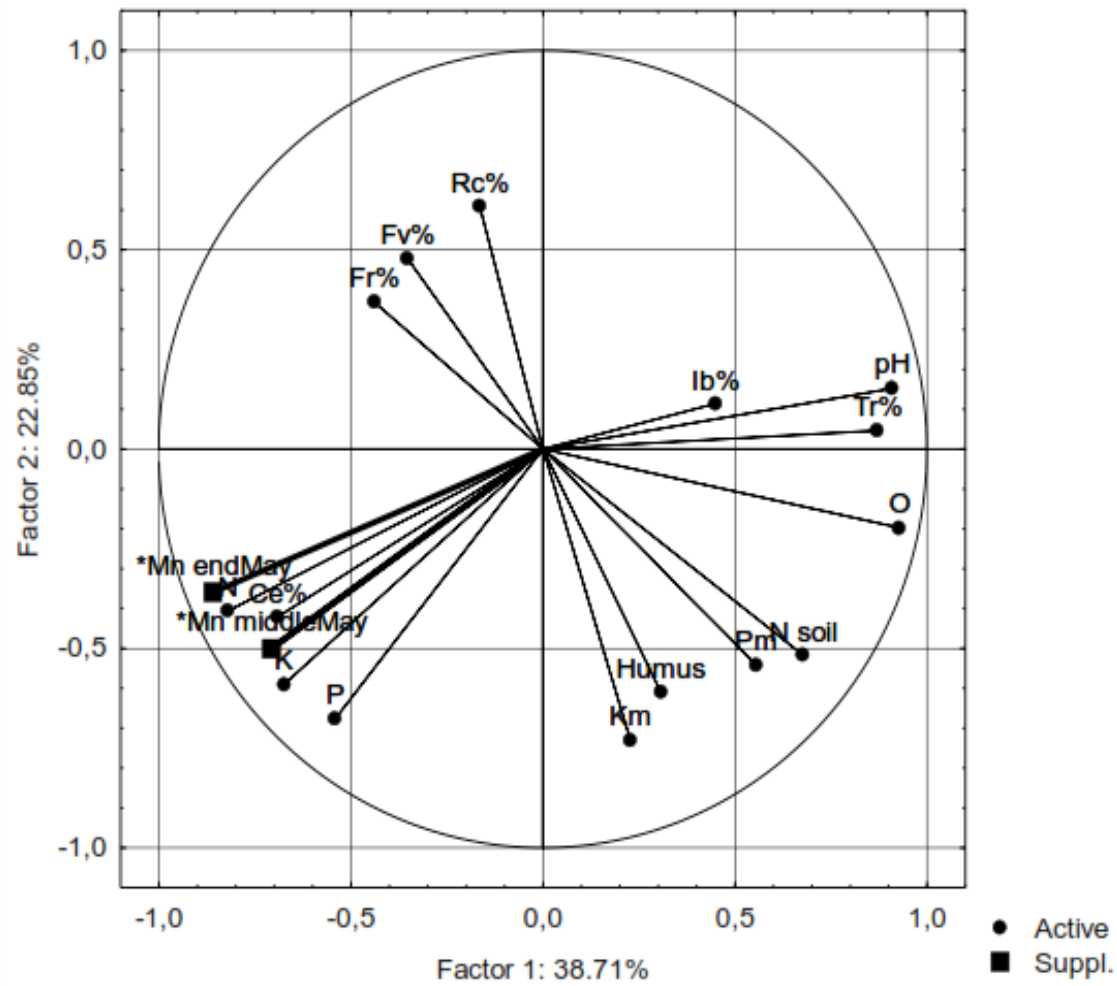

Figure 2. The PC\&CA projection of active and supplementary variables on the PC1xPC2 plane 
Table 2. The correlation coefficients (selectively) of PC\&CA multivariate approach

\begin{tabular}{ccccccccccccccc}
\hline $\begin{array}{c}\text { Varia- } \\
\text { ble }\end{array}$ & $\mathbf{0}$ & $\mathbf{N}$ & $\mathbf{P}$ & $\mathbf{K}$ & $\begin{array}{c}\mathbf{p H} \\
\text { soil }\end{array}$ & $\begin{array}{c}\mathbf{H} \\
\text { soil }\end{array}$ & $\begin{array}{c}\mathbf{N} \\
\text { soil }\end{array}$ & $\begin{array}{c}\mathbf{P m} \\
\text { soil }\end{array}$ & $\begin{array}{c}\mathbf{K m} \\
\text { soil }\end{array}$ & $\mathbf{C e} \%$ & $\mathbf{F r} \%$ & Tr\% & $\mathbf{I b \%}$ & $\mathbf{F v \%}$ \\
\hline $\mathrm{Ce} \%$ & -0.48 & 0.90 & 0.48 & 0.54 & -0.45 & & & & & & & & & \\
\hline $\mathrm{Tr} \%$ & 0.83 & -0.66 & -0.58 & -0.57 & 0.70 & & & & & & & & & \\
\hline$* \mathrm{Mn} 1$ & -0.65 & 0.74 & 0.90 & 0.75 & -0.69 & 0.09 & -0.26 & -0.09 & 0.09 & 0.61 & 0.31 & -0.73 & -0.03 & -0.07 \\
\hline$* \operatorname{Mn} 2$ & -0.70 & 0.88 & 0.69 & 0.81 & -0.86 & -0.04 & -0.39 & -0.28 & 0.05 & 0.71 & 0.44 & -0.79 & -0.28 & 0.09 \\
\hline
\end{tabular}

Note: *supplementary variables; Mn 1 - spring content in the middle of May (ppm); Mn 2 - spring content at the end of May (ppm); soil Km and Pm (ppm); soil Kjeldahl N (\%); Humus (\%).

Analyzing the realistic data, it was influenced negatively the spring Mn contents of forage by fermented sheep manure management system. In the climatic and soil conditions of the hill Banat region, the correlation coefficients between organic fertilizer data and Mn content of forage from grassland microecosystems was -0.65 in the middle of May and - 0.70 at the end of May. Organic management system based on exclusive fermented sheep manure application improved the Trifolium repens (\%) presence in grassland biomass, the correlation coefficient being 0.83 . The correlation between Trifolium repens (\%) presence in grassland perennial covering, influenced positively by organic fertilization, and spring Mn content of forage had negative and high coefficient: -0.73 in the middle of May and -0.79 at the end of the May. Militimore et al. (1970) observed that in legume hay used for ruminants' feeding is necessary to supplement the diet with Mn.

It is recommended that 2D graph of variables multiresponse (Figure 2) be related to the correlation coefficients presented in Tab 2.

In the spring conditions of grassland from Banat hill, the mineral fertilization and soil acidifying influenced positively the Mn content of perennial forage. Between soil $\mathrm{pH}$ realistic values and spring Mn content of grassland microecosystems forage the correlation coefficients were high and negatively: -0.69 and -0.86 in the middle and respectively at the end of May. The coefficients were high and positive for the correlations between spring Mn contents and the NPK mineral fertilizers data, both in the middle and at the end of
May: 0.74 and 0.88 in mineral nitrogen case; 0.90 and 0.69 in mineral phosphorus fertilization case; 0.75 and 0.81 in mineral potassium fertilization case. Mineral fertilization acidified the soil $\mathrm{pH}$ and increased the presence of Calamagrostis epigejos (\%) in perennial grassland covering, especially mineral nitrogen application, the correlation coefficient for Ce (\%) - $\mathrm{N}$ fertilization data being 0.9 . The Calamagrostis epigejos (\%) presence and forage Mn content, both in the middle and at the end of May, had the correlation coefficients 0.61 and 0.71 respectively.

These results have shown that in the Banat hill conditions, the Mn spring content of perennial grassland forage was higher in exclusive mineral fertilization cases than in mixed organic - mineral, exclusive organic management or unfertilized microecosystems, even the soil Mn average values were: 237 ppm (M1-M3), 239 ppm (OM1-OM3), 249 ppm (01-03), and 225 ppm (M). Cheng and Ouellette (1970) and Dash et al. (2010) reported also that fertilization with mineral nitrogen increase the Mn uptake by plants from the soil, comparatively with organic fertilizers sources, both by soil $\mathrm{pH}$ changes and oxidation-reduction mechanisms. According with Pedas et al. (2011), in organic fertilization case the Mn deficiency occurs, correlated with soil phosphorus content increasing.

Considering all the aspects presented in this research, PC\&CA multivariate technique can be a flexible tool to analyze high amount of experimental data in a comprehensive way, rapid and with a friendly interface, for understand better 
the natural complex phenomena from perennial grassland influenced by organic and/or mineral fertilization, regarding the Mn content of forage in spring. PC\&CA can be also useful to develop smart and sustainable management systems for grassland ecosystem, for each territorial administrative unit, to obtain natural fortified forage in Mn depending on local soil characteristics and clime conditions.

\section{CONCLUSION}

The recorded data have shown that, in normal soil and clime conditions of Banat hills, the highest spring Mn content (average value) was determined for the forage from exclusive mineral fertilization microecosystems of perennial grassland, both in the middle and at the end of May, even the highest Mn content of soil was in exclusive organic system.

Considering the forage of all studied grassland microecosystems, the Mn content (average value) decreased from the middle to the end of May, and from exclusive NPK mineral fertilization, to mixed fertilizers application and exclusive organic management system. In the middle of month, the forage $\mathrm{Mn}$ content (average value) was in 89 $222 \mathrm{ppm}$ range, while at the end of month varied between 66 - $141 \mathrm{ppm}$. In grassland soil, the average value of Mn content decreased from 249 ppm in organic management system, to $239 \mathrm{ppm}$ in mixed fertilization microecosystems, $237 \mathrm{ppm}$ in exclusive NPK mineral fertilization cases and $225 \mathrm{ppm}$ in unfertilized trial.

PC\&CA multivariate technique, used as statistical tool to analyze the 17 variables for the ten studied microecosystems, extracted useful information regarding the bioavailability of soil Mn for grassland plants, depending on soil acidification by fertilization in local clime conditions. The exclusive NPK mineral fertilization management determined the acidification of soil and increasing of $\mathrm{Mn}$ uptake by the grassland plants. The correlation coefficients highlighted also the positive influence of nitrogen mineral fertilizers on Calamagrostis epigejos presence in grassland perennial covering (0.9), and the correlation between $\mathrm{Ce} \%$ and forage $\mathrm{Mn}$ content in the middle (0.61) and at the end of May (0.71). Trifolium repens presence was stimulated by fermented sheep manure (0.83), but the forage $\mathrm{Mn}$ content (average value) in spring was the smallest in these microecosystems, both in the middle (89 $\mathrm{ppm}$ ) end at the end (66 ppm) of May.

The Mn content of grassland forage should be a routine analysis for feed quality estimation. A natural functional forage for animals feeding, from grassland ecosystem, with an optimum content in Mn is recommended.

Acknowledgments. The results of Mn content of the perennial grassland forage in the middle and at the end of May, floristic matrix and soil characteristics selected for this PC\&CA multivariate approach were obtained with the financial support of Grant BD/CNCSIS Romania: "On the influence of substances flows on the quality of forage from grassland", 2007-2009 (www.cncsis.ro).

\section{REFERENCES}

1. Bhuvaneswari DC, Kiran KK, Jyotsna V, Indravathi G (2014). Manganese Induced Toxic Effects on Oxidative System and mRNA Expression of Mn-Sod and Gpx in Albino Rat Brain: Protective Effect of AlphaTocopherol. International Journal of Innovative Research in Science, Engineering and Technology, vol. 3 (2): 9252-9263.

2. Cailliatte R, Schikora A, Briat JF, Mari S, Curie C (2010). High-Affinity Manganese Uptake by the Metal Transporter NRAMP1 Is Essential for Arabidopsis Growth in Low Manganese Conditions. The Plant Cell, vol. 22: 904-917.

3. Cheng BT, Ouellette GJ (1970). Effect of various nitrogen fertilizers on manganese and iron availability as measured by incubation and sand culture studies. Can. J. Soil Sci. 50: 163-170.

4. Dash Debiprasad, Patro Hrusikesh, Tiwari Ramesh C, Shahid Mohammad (2010). Effect of organic and inorganic sources of nitrogen on $\mathrm{Fe}, \mathrm{Mn}, \mathrm{Cu}$ and $\mathrm{Zn}$ uptake and content of rice grain at harvest and straw at different stages of rice (Oryza sativa) crop growth. Advances in Applied Science Research 1 (3): 36-49.

5. Eijkelkamp BA, Morey JR, Ween MP, Ong C-IY, McEwan AG, Paton JC, McDevitt CA (2014). Extracellular Zinc Competitively Inhibits Manganese Uptake and Compromises Oxidative Stress Management in Streptococcus pneumoniae. PLoS ONE 9 (2): e89427, doi:10.1371/journal.pone.0089427

6. Erikson KM, Aschner M (2006). Increased manganese uptake by primary astrocyte cultures with altered iron status is mediated primarily by divalent metal transporter. Neurotoxicology 27 (1):125-130.

7. Fernando DR, Lynch JP (2015). Manganese phytotoxicity: new light on an old problem. Annals of Botany 116: 313-319. 
8. Frick R, Müller-Edenborn B, Schlicker A, RothenRutishauser B, Raemy DO, Günther D, Hattendorf B, Stark W, Beck-Schimmer B (2011). Comparison of manganese oxide nanoparticles and manganese sulfate with regard to oxidative stress, uptake and apoptosis in alveolar epithelial cells. Toxicology Letters, 205 (2):163-172.

9. Gergen I, Harmanescu M (2012). Application of principal component analysis in the pollution assessment with heavy metals of vegetable food chain in the old mining areas. Chem. Cent. J. 6: 156, DOI 10.1186/1752-153X-6-156.

10. Harmanescu M (2012). Comparative researches on two direct transmethylation without prior extraction methods for fatty acids analysis in vegetal matrix with low fat content. Chem. Cent. J. 6: 8, DOI 10.1186/1752153X-6-8.

11. Hidiroglou M. (1979). Manganese in ruminant nutrition. Can J Anim Sci., 59: 217-236.

12. Holley AK, Bakthavatchalu V, Velez-Roman JM, St. Clair DK (2011). Manganese Superoxide Dismutase: Guardian of the Powerhouse. Int. J. Mol. Sci. 12: 71147162.

13. Hur Gwong-Cheung, Sung Jin Cho, Chan-Hyung Kim, Min Kyu Kim, Soo In Bae, Seon Young Nam, Jong-Wan Park, Woo Ho Kim, Byung Lan Lee (2003). Manganese Superoxide Dismutase Expression Correlates with Chemosensitivity in Human Gastric Cancer Cell Lines. Clinical Cancer Research, 9: 5768-5775.

14. Ianos Gh, Pusca I, Goian M (1997). Solurile Banatului. Conditii naturale si fertililtate, Editura Mirton, Timisoara.

15. Khan Zafar Iqbal, Kafeel Ahmad, Muhammad Ashraf, Syed Ali Hassan Naqvi, Alireza Seidavi, Nudrat Aisha Akram, Vito Laudadio, Vincenzo Tufarelli (2015). Evaluating pasture and soil allowance of manganese for Kajli rams grazing in semi-arid environment. Trop Anim Health Prod 47: 563-566.

16. Kim Yeon Soo, Piyushi Gupta Vallur, Rébécca Phaëton, Karthikeyan Mythreye, Nadine Hempel (2017). Insights into the Dichotomous Regulation of SOD2 in Cancer. Antioxidants, 6: 86; doi:10.3390/antiox6040086.

17. Kisidayova S, Pristas P, Zimovcakova M, Blanar Wencelova M, Homolova L, Mihalikova K, Cobanova K, Gresakova L, Varadyova Z (2018). The effects of high dose of two manganesesupplements (organicand inorganic) on the rumen microbial ecosystem. PLoS ONE 13 (1): e0191158.https://doi.org/10.1371/ journal. pone.0191158.

18. Kizaki Masahiro, Sakashita Akiko, Karmakar Amitabha, Lin Chi-Whei, Koeffler H Phillip (1993). Regulation of Manganese Superoxide Dismutase and Other Antioxidant Genes in Normal and Leukemic Hematopoietic Cells and Their Relationship to
Cytotoxicity by Tumor Necrosis Factor Blood, 82(4):1142-1150.

19. Kumar Sudhir, Anil Kumar Pandey, Waquar Ahmed Abdul Razzaque, Dinesh Kumar Dwivedi (2011). Importance of micro minerals in reproductive performance of livestock. Veterinary World, 4 (5): 230 233.

20. Leplat F, Pedas PR, Rasmussen SK, Husted S (2016). Identification of manganese efficiency candidate genes in winter barley (Hordeum vulgare) using genome wide association mapping. Genomics 17: 775, DOI 10.1186/s12864-016-3129-9.

21. Markiewicz-Górka Iwona, Lidia Januszewska, Aleksandra Michalak, Adam Prokopowicz, Ewa Januszewska, Natalia Pawlas, Krystyna Pawlas (2015). Effects of chronic exposure to lead, cadmium, and manganese mixtures on oxidative stress in rat liver and heart. Arh Hig Rada Toksikol, 66: 51-62.

22. Meteorological Station Archive. Oravita. Caras-Severin district (the clime data). Millaleo R, Reyes-Díaz $M$, Ivanov AG, Mora ML, Alberdi M (2010). Manganese as essential and toxic element for plants: transport, accumulation and resistance mechanisms. J. Soil Sci. Plant Nutr. 10 (4): 476 - 494.

23. Militimore JE, Mason JL, Ashby DL (1970). Copper, Zinc, Manganese and Iron Variation in Five Feeds for Ruminants. Can. J. Anim. Sci. 50: 293-300.

24. Mirmohammadi S. (2014). Manganese Exposure and Toxicity. J Pollut Eff Cont 2: 116, http://dx.doi. org/10.4172/2375-4397.1000116.

25. Neal AP, Guilarte TR (2012). Mechanisms of Heavy Metal Neurotoxicity: Lead and Manganese. J Drug Metab Toxicol S5: 002. doi:10.4172/2157-7609.S5002.

26. Pedas Pai, Husted Søren, Skytte Kristian, Schjoerring Jan Kofod (2011). Frontiers in Plant Science. Plant Nutrition, 2, article 37: 1-12.

27. Santamaria AB (2008). Manganese exposure, essentiality \& toxicity. Indian J Med Res 128: 484-500.

28. Schubert TS (1992). Manganese toxicity of plants in Florida. Plant Pathology Circular no. 353, Fla. Dept. Agric. \& Consumer Services, Division of Plant Industry.

29. Socha AL, Guerinot ML (2014). Mn-euvering manganese: the role of transporter gene family members in manganese uptake and mobilization in plants. Frontiers in Plant Science, vol.5, article 106, doi 10.3389/fpls.2014.00106.

30. SR ISO 10390 (1999). Calitatea solului. Determinarea pH-ului.

31. Stoica E coord., Rauta C, Florea N (1986). Metode de analiza chimica a solului. Bucuresti. 
32. Zhang Hao, Haitao Nie, Ziyu Wang, Feng Wang (2018). The net iron, manganese, copper, and zinc requirements for maintenance and growth of Dorper $\times \mathrm{Hu}$ ewe lambs. Italian Journal of Animal Science, DOI: 10.1080/1828051X.2018.1431964.

33. Zhang Qin, Enchun Pan, Linfei Liu, Wei $\mathrm{Hu}$, Yuan He, Qiujin Xu, Cunzhen Liang (2014). Study on the Relationship between Manganese Concentrations in
Rural Drinking Water and Incidence and Mortality Caused by Cancer in Huai'an City. BioMed Research International, article ID 645056, 5 pages, DOI. org/10.1155/2014/645056.

34. Register (EC) No 1831/2003. European Union Register of Feed Additives. Edition 250. Appendixes 3e, 4-24.01.2017. 